\title{
Effects of canagliflozin compared with placebo on major adverse cardiovascular and kidney events in patient groups with different baseline levels of $\mathrm{HbA}_{1 \mathrm{c}}$ disease duration and treatment intensity: results from the CANVAS Program
}

\author{
Tamara K. Young $^{1}$ (D) - Jing-Wei Li ${ }^{1}$ - Amy Kang ${ }^{1} \cdot$ Hiddo J. L. Heerspink ${ }^{1}$ - Carinna Hockham ${ }^{2} \cdot$ Clare Arnott $^{1,3}$. \\ Brendon L. Neuen ${ }^{1}$. Sophia Zoungas ${ }^{1,4} \cdot$ Kenneth W. Mahaffey ${ }^{5}$. Vlado Perkovic ${ }^{1}$ - Dick de Zeeuw ${ }^{6} \cdot$ Greg Fulcher $^{3}$. \\ Bruce Neal ${ }^{1} \cdot$ Meg Jardine $^{1,3}$
}

Received: 10 December 2020 / Accepted: 19 April 2021 / Published online: 26 August 2021

(C) The Author(s) 2021

\begin{abstract}
Aims/hypothesis Type 2 diabetes mellitus can manifest over a broad clinical range, although there is no clear consensus on the categorisation of disease complexity. We assessed the effects of canagliflozin, compared with placebo, on cardiovascular and kidney outcomes in the CANagliflozin cardioVascular Assessment Study (CANVAS) Program over a range of type 2 diabetes mellitus complexity, defined separately by baseline intensity of treatment, duration of diabetes and glycaemic control.

Methods We performed a post hoc analysis of the effects of canagliflozin on major adverse cardiovascular events (MACE) according to baseline glucose-lowering treatments ( 0 or 1, 2 or 3+ non-insulin glucose-lowering treatments, or insulin-based treatment), duration of diabetes $\left(<10,10\right.$ to $16,>16$ years) and $\mathrm{HbA}_{1 \mathrm{c}}(\leq 53.0 \mathrm{mmol} / \mathrm{mol}[<7.0 \%],>53.0$ to $58.5 \mathrm{mmol} / \mathrm{mol}[>7.0 \%$ to $7.5 \%],>58.5$ to $63.9 \mathrm{mmol} / \mathrm{mol}$ [ $>7.5$ to $8.0 \%$ ], $>63.9$ to $69.4 \mathrm{mmol} / \mathrm{mol}[8.0 \%$ to $8.5 \%$ ], $>69.4$ to $74.9 \mathrm{mmol} / \mathrm{mol}$ [ $>8.5$ to $9.0 \%$ ] or $>74.9 \mathrm{mmol} / \mathrm{mol}$ [>9.0\%]). We analysed additional secondary endpoints for cardiovascular and kidney outcomes, including a combined kidney outcome of sustained $40 \%$ decline in eGFR, end-stage kidney disease or death due to kidney disease. We used Cox regression analyses and compared the constancy of HRs across subgroups by fitting an interaction term ( $p$ value for significance $<0.05$ ).

Results At study initiation, 5095 (50\%) CANVAS Program participants were treated with insulin, $2100(21 \%)$ had an $\mathrm{HbA}_{1 \mathrm{c}}>$ $74.9 \mathrm{mmol} / \mathrm{mol}(9.0 \%)$ and the median duration of diabetes was 12.6 years (interquartile interval 8.0-18 years). Canagliflozin reduced MACE (HR 0.86 [95\% CI 0.75, 0.97]) with no evidence that the benefit differed between subgroups defined by the number of glucose-lowering treatments, the duration of diabetes or baseline $\mathrm{HbA}_{1 \mathrm{c}}$ (all p-heterogeneity >0.17). Canagliflozin reduced MACE in participants receiving insulin with no evidence that the benefit differed from other participants in the trial (HR 0.85 [95\% CI 0.72, 1.00]). Similar results were observed for other cardiovascular outcomes and for the combined kidney outcome (HR for combined kidney outcome 0.60 [95\% CI 0.47, 0.77]), with all p-heterogeneity $>0.37$.

Conclusions/interpretation In people with type 2 diabetes mellitus at high cardiovascular risk, there was no evidence that cardiovascular and renal protection with canagliflozin differed across subgroups defined by baseline treatment intensity, duration of diabetes or $\mathrm{HbA}_{1 \mathrm{c}}$.
\end{abstract}

Keywords Baseline $\mathrm{HbA}_{1 \mathrm{c}} \cdot$ Complications $\cdot$ Disease duration · Treatment intensity · Type 2 diabetes complexity

Carinna Hockham

chockham@georgeinstitute.org.uk

Clare Arnott

carnott@georgeinstitute.org.au

1 The George Institute for Global Health, UNSW, Sydney, NSW, Australia

2 The George Institute for Global Health, Imperial College London, London, UK
University of Sydney, Sydney, NSW, Australia

4 Monash University, Melbourne, VIC, Australia

5 Stanford Center for Clinical Research, Department of Medicine, Stanford University School of Medicine, Stanford, CA, USA

6 Department of Clinical Pharmacy and Pharmacology, University Medical Center Groningen, Groningen, the Netherlands 


\section{Research in context}

\section{What is already known about this subject?}

- SGLT2 inhibitors such as canagliflozin have demonstrated protective effects in prevention of cardiovascular and clinical kidney events

- It is unclear if these effects are consistent across a spectrum of diabetes clinical presentations

- There is no universally accepted system to define diabetes complexity; however, treatment intensity, disease duration and $\mathrm{HbA}_{1 \mathrm{c}}$ are clinically relevant surrogate markers

\section{What is the key question?}

- Does canagliflozin reduce cardiovascular and clinical kidney events in all patients with diabetes, irrespective of their baseline disease status?

\section{What are the new findings?}

- There was no evidence of a difference in the relative risk reduction achieved with canagliflozin compared with placebo for a cardiovascular or clinical kidney event, regardless of baseline treatment intensity, disease duration or $\mathrm{HbA}_{1 c}$

\section{How might this impact on clinical practice in the foreseeable future?}

- Consideration should be given for utilising this class of medication, even in patients with more serious prognostic factors, for the prevention of cardiovascular and kidney complications in patients with type 2 diabetes mellitus

$\begin{array}{ll}\begin{array}{l}\text { Abbreviations } \\ \text { CANVAS }\end{array} & \begin{array}{l}\text { CANagliflozin cardioVascular } \\ \text { Assessment Study }\end{array} \\ \text { CANVAS-R } & \begin{array}{l}\text { CANagliflozin cardioVascular } \\ \text { Assessment Study - Renal }\end{array} \\ \text { IQI } & \begin{array}{l}\text { Interquartile interval } \\ \text { MACE }\end{array} \\ \text { Major adverse cardiovascular events } \\ \text { SGLT2 } & \text { Sodium-glucose cotransporter 2 } \\ \text { UACR } & \text { Urinary albumin/creatinine ratio }\end{array}$

\section{Introduction}

Type 2 diabetes mellitus is a chronic disease, and individuals included in large trials vary widely in terms of their glycaemic control and treatment management strategies. However, there is no universally agreed system for classifying the complexity of diabetes mellitus. A higher level of treatment intensity, increased disease duration and an elevated $\mathrm{HbA}_{1 \mathrm{c}}$ all imply a more complex disease state $[1,2]$. The intensity of diabetes treatment is a surrogate marker of diabetes complexity in the context of international guidelines framed around glycaemic control [3]. Disease duration is another possible variable to describe disease complexity and is independently associated with increased morbidity and mortality risk, reflecting an underlying progressive disease course [1, 4, 5]. $\mathrm{HbA}_{1 \mathrm{c}}$ level is a biochemical predictor of the development of microvascular complications [6-8], reflected in $\mathrm{HbA}_{1 \mathrm{c}}$ thresholds appearing as targets for guideline-directed therapy [8-10]. Overall, these variables represent different aspects of a heterogeneous disease.

Sodium-glucose cotransporter 2 (SGLT2) inhibitors reduce cardiovascular events in people with type 2 diabetes mellitus and high cardiovascular risk [11-15]. The SGLT2 inhibitor canagliflozin has also been demonstrated to reduce the progression of chronic kidney disease and prevent clinical kidney events [11, 12]. Despite the requirement of these agents to be filtered at the glomerulus to meet their site of action, canagliflozin shows consistent kidney and cardiovascular protection across declining categories of eGFR [15, 16]. However, the effectiveness of these agents in differing states of glycaemia and diabetes severity is unclear and may plausibly vary depending on the underlying glycaemic control and the extent of preexisting diabetes-related complications [17-19].

The aim of these analyses was to assess the protective effect of canagliflozin on key cardiovascular and kidney outcomes across a broad range of diabetes severity at treatment initiation. In the absence of a consensus for classification of diabetes severity or complexity, our assessment for the treatment efficacy and safety of canagliflozin in the CANagliflozin cardioVascular Assessment Study (CANVAS) Program on cardiovascular and kidney outcomes was undertaken according to three different variables: diabetes treatment intensity, diabetes duration and baseline $\mathrm{HbA}_{1 \mathrm{c}}$. 


\section{Methods}

\section{Study design and participants}

The CANVAS Program comprised two multicentre, doubleblind, placebo-controlled, randomised trials (CANVAS and CANagliflozin cardioVascular Assessment Study - Renal [CANVAS-R]). These were similarly conducted, with a prespecified integrated analysis, and with the aim of assessing the cardiovascular efficacy and safety of canagliflozin in participants with type 2 diabetes and either a history of, or at high risk for, CVD. The two trials were scheduled for joint close-out and analysis when at least 688 cardiovascular events had occurred, and the last randomised participant had undergone at least 78 weeks of follow-up [20]. Local institutional ethics committees approved the trial protocols at each site. Trials were registered and details are available online (ClinicalTrials.gov registration no. NCT01032629 and NCT01989754). All participants provided written, informed consent to participate. The trial protocols and statistical analysis plans were published along with the primary CANVAS Program manuscript [11].

\section{Study population}

Entry criteria for both trials included participants with type 2 diabetes $\left(53.0 \mathrm{mmol} / \mathrm{mol}[7.0 \%] \leq \mathrm{HbA}_{1 \mathrm{c}} \leq 91.3 \mathrm{mmol} / \mathrm{mol}\right.$ [10.5\%]) who were either $\geq 30$ years old with established atherosclerotic vascular disease or $\geq 50$ years old with two or more cardiovascular risk factors. Risk factors were defined as: duration of diabetes of at least 10 years; systolic blood pressure $>140 \mathrm{mmHg}$ while receiving one or more antihypertensive agents; current smoking; microalbuminuria or macroalbuminuria; or high-density lipoprotein cholesterol level of less than $1 \mathrm{mmol} / \mathrm{l}(38.7 \mathrm{mg} / \mathrm{dl})$.

\section{Baseline diabetes variable definitions}

This post hoc analysis was designed after the main study was published. The analysis plan for the current analyses, including the definition of the baseline subgroups, was prespecified prior to commencement of these analyses.

Participants were divided into subgroups for treatment intensity, disease duration and baseline $\mathrm{HbA}_{1 \mathrm{c}}$, according to the following definitions:

(1) Treatment intensity Subgroups for treatment intensity were defined by glucose-lowering treatments at baseline study visit and were: zero or one oral glucose-lowering agent, two oral glucose-lowering agents, three or more oral glucose-lowering agents, or any combination of glucose-lowering medication that included insulin therapy.
(2) Disease duration Subgroups were defined by tertiles of disease duration at baseline, namely: duration of $<10$ years, $10-16$ years or $>16$ years.

(3) Baseline $\mathbf{H b A}_{\mathbf{1 c}}$ Baseline $\mathrm{HbA}_{1 \mathrm{c}}$ was measured 2 weeks prior to randomisation. Subgroups of $\mathrm{HbA}_{1 \mathrm{c}}$ were defined on clinically accepted categories of $\mathrm{HbA}_{1 \mathrm{c}}$ of $\leq 53.0 \mathrm{mmol} / \mathrm{mol}(<7.0 \%),>53.0$ to $58.5 \mathrm{mmol} / \mathrm{mol}$ (>7.0\% to $7.5 \%),>58.5$ to $63.9 \mathrm{mmol} / \mathrm{mol}(>7.5 \%$ to $8.0 \%$ ), $>63.9$ to $69.4 \mathrm{mmol} / \mathrm{mol}(>8.0 \%$ to $8.5 \%)$, $>69.4$ to $74.9 \mathrm{mmol} / \mathrm{mol}(>8.5 \%$ to $9.0 \%)$ and $>74.9 \mathrm{mmol} / \mathrm{mol}(>9.0 \%)$.

\section{Randomisation and conduct of the CANVAS Program trials}

A web-based response system was used for computer-generated random allocation. In CANVAS, participants were randomly assigned to canagliflozin $100 \mathrm{mg}$ daily, canagliflozin $300 \mathrm{mg}$ daily or placebo. In CANVAS-R, they were randomly assigned to canagliflozin $100 \mathrm{mg}$ daily with potential dose escalation or matching placebo. Face-to-face follow-up was scheduled in three visits during the first year and at 6 month intervals thereafter, with telephone follow-up between face-to-face assessments. Adverse events were collected and reported separately. Ongoing glycaemic management was in accordance with local guidelines. Central endpoint adjudication committees blinded to treatment allocation assessed cardiovascular, kidney and key safety outcomes. The trials were analysed and reported together $[11,20]$.

\section{Outcomes}

The outcomes selected for this post hoc analysis were the same as those used in the primary reporting of the CANVAS Program [11]. Other prespecified secondary cardiovascular outcomes were death from CVD, myocardial infarction, stroke and a combined outcome comprising either cardiovascular death or admission for heart failure [11].

The kidney outcome was a composite of end-stage kidney disease, kidney death and 40\% decrease in eGFR, which was required to be sustained for two consecutive measures of $\geq 30$ days apart or occurring on the last available measure to ensure the measures reflected chronic progression [11]. Albuminuria progression comprised more than a $30 \%$ increase in albuminuria and a change either from normoalbuminuria to microalbuminuria or macroalbuminuria, or from microalbuminuria to macroalbuminuria. The Modification of Diet in Renal Disease study equation to define eGFR was used as in the primary analysis. Albuminuria was measured in first morning void urine specimens and calculated as the urinary albumin/creatinine ratio (UACR). 


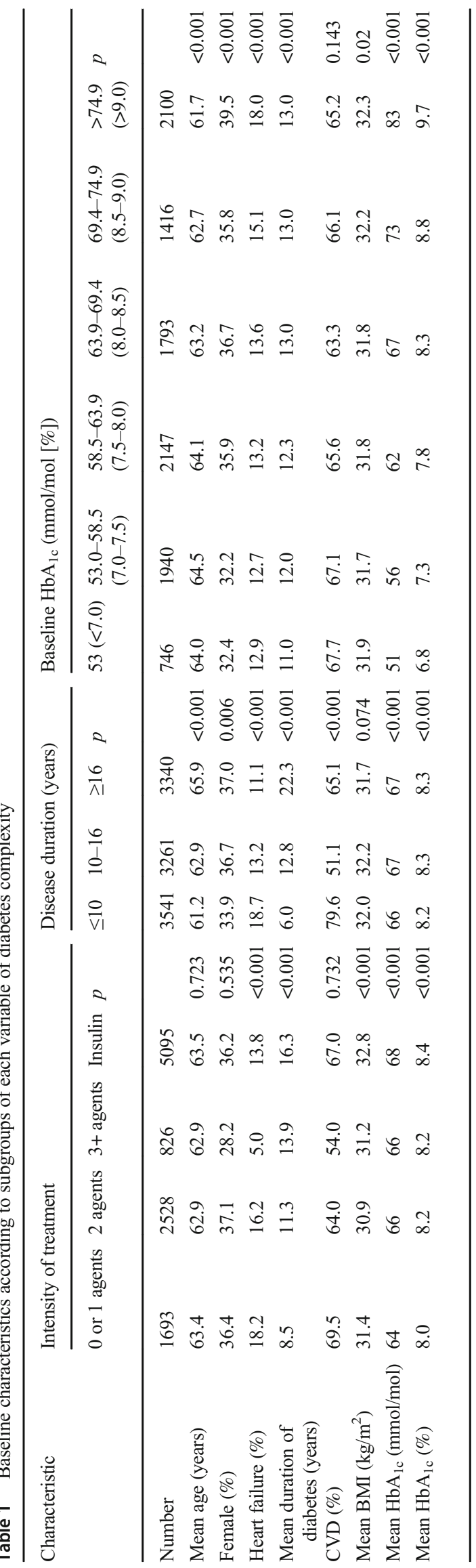




\section{Statistical analysis}

Baseline characteristics with continuous data were described using mean (SD) or, when non-normally distributed, using median (interquartile interval [IQI]). Categorical data were described as frequencies and percentages. Differences in characteristics between subgroups were examined using a linear trend test from generalised linear models for continuous variables and Cochran-Armitage trend test for discrete variables.

HRs for the effect of canagliflozin compared with placebo, 95\% CIs and $p$ values were estimated with Cox regression models, using an intention-to-treat approach, with stratification according to trial and history of CVD. Comparisons across subgroups were assessed for heterogeneity, with a $p$ value of less than 0.05 regarded as significant. The global $p$ values for heterogeneity across all subgroups were obtained by fitting an interaction term in the Cox regression model.

Restricted cubic splines using columns that were univariate spline expansions of disease duration and baseline $\mathrm{HbA}_{1 \mathrm{c}}$ were fitted to proportional hazard regression to generate dose-response figures, setting point estimates at the middle of each category, for the major adverse cardiovascular events (MACE) outcome.

All analyses were performed using SAS version 9.4 (SAS Institute, Cary, NC, USA).

\section{Results}

The CANVAS Program included a total of 10,142 participants, 4330 participants in the CANVAS trial and 5812 participants in the CANVAS-R trial. Across the program, 5795 participants were randomised to canagliflozin and 4347 were randomised to placebo. During a mean follow-up of 188.2 weeks, 1011 participants experienced the combined MACE outcome. Canagliflozin reduced MACE (HR 0.86 [95\% CI 0.75, 0.97]), and the combined kidney outcome (HR 0.60 [95\% CI 0.47, 0.77]), as previously published elsewhere [11].

At study initiation, 5095 (50\%) CANVAS Program participants were treated with insulin. The median duration of diabetes was 12.6 years (interquartile interval $8.0-18$ years). In total, 2100 participants $\left(21 \%\right.$ ) had a baseline $\mathrm{HbA}_{1 \mathrm{c}}$ greater than $74.9 \mathrm{mmol} / \mathrm{mol}(9.0 \%)$. In general, the markers of disease severity at baseline were consistent between the three variables (Table 1). Mean $\mathrm{HbA}_{1 \mathrm{c}}$ was lowest in the participants on zero or one agent at baseline (mean $64 \mathrm{mmol} / \mathrm{mol}[8.0 \%$, SD $0.9 \%]$ ) and highest in those on insulin therapy (mean $68 \mathrm{mmol} / \mathrm{mol}$ [8.4\%, SD 0.9\%]). Mean disease duration was shortest in the participants on zero or one agent at baseline (mean 8.5 years, SD 6.2 years) and longest in those on insulin therapy (mean 16.3 years, SD 7.7 years). Mean disease duration was shortest for those with the lowest $\mathrm{HbA}_{1 \mathrm{c}}$ category at baseline (mean 11.0 years, IQI 6-16 years) and longest for those with the highest three $\mathrm{HbA}_{1 \mathrm{c}}$ categories at baseline (all mean 13.0 years) (Electronic supplementary material [ESM] Figs. 1, 2; ESM Tables 1-3).

Albuminuria was different among $\mathrm{HbA}_{1 \mathrm{c}}$ subgroups $(p<0.05)$, although there was no discernible difference in eGFR. For example, participants in the lowest $\mathrm{HbA}_{1 \mathrm{c}}$ subgroup had less albuminuria (median UACR $1.1 \mathrm{mg} / \mathrm{mmol}$, IQI $1.0-2.6 \mathrm{mg} / \mathrm{mmol}$ ) compared with those in the highest $\mathrm{HbA}_{1 \mathrm{c}}$ category (median UACR $2.0 \mathrm{mg} / \mathrm{mmol}$, IQI 0.9 $8.0 \mathrm{mg} / \mathrm{mmol}$ ). Both albuminuria and eGFR were different between disease duration subgroups $(p<0.05$ for both). Participants with the shortest disease duration had higher eGFR and lower albuminuria than those with the longest disease duration (mean eGFR $80.0 \mathrm{ml} \mathrm{min}^{-1}[1.73 \mathrm{~m}]^{-2}$, SD $20.3 \mathrm{ml} \mathrm{min}{ }^{-1}[1.73 \mathrm{~m}]^{-2}$, median UACR $1.2 \mathrm{mg} / \mathrm{mmol}$, IQI $0.7-3.4 \mathrm{mg} / \mathrm{mmol}$; and mean eGFR $71.6 \mathrm{ml} \mathrm{min}^{-1}[1.73 \mathrm{~m}]^{-2}$, SD $19.9 \mathrm{ml} \mathrm{min}^{-1}[1.73 \mathrm{~m}]^{-2}$, median UACR $1.8 \mathrm{mg} / \mathrm{mmol}$, IQI $0.8-7.3 \mathrm{mg} / \mathrm{mmol}$, respectively). Similarly, both albuminuria and eGFR were different in treatment intensity subgroups ( $p<0.05$ for both). Participants with the lowest intensity of treatment had higher eGFR and lower albuminuria than those receiving insulin-based treatment (mean eGFR $77.7 \mathrm{ml} \mathrm{min}^{-1}$

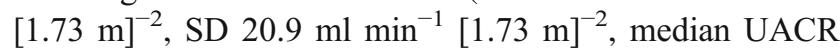
$1.1 \mathrm{mg} / \mathrm{mmol}$, IQI $0.7-2.8 \mathrm{mg} / \mathrm{mmol}$; and mean eGFR

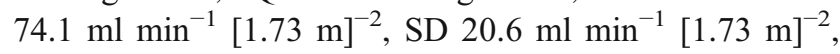
median UACR $1.7 \mathrm{mg} / \mathrm{mmol}$, IQR $0.8-7.0 \mathrm{mg} / \mathrm{mmol}$, respectively) (ESM Tables 1-3).

\section{Outcomes according to treatment intensity}

When considering the reduction in MACE for the overall trial population (HR 0.86 [CI 0.75, 0.97]), there was no evidence that the benefit differed across subgroups of baseline treatment intensity (HR 0.71 [CI 0.51, 0.99], HR 0.95 [CI 0.71, 1.26], HR 1.02 [CI $0.59,1.76$ ], HR 0.85 [CI $0.72,1.0$ ] for 0 or 1,2 or $3+$ glucose-lowering agents, or insulin-based therapy, respectively; p-heterogeneity 0.292). The point estimates of the HRs suggested a potential benefit for the individual cardiovascular outcomes; however, the CIs around the overall effect and the effects within each subgroup were wide and overlapped the null, so it was not possible to draw definitive conclusions (Fig. 1a).

There was consistency across treatment intensity categories for the reduction of the kidney disease outcome of sustained $40 \%$ decrease in eGFR, end-stage kidney disease or kidney

Fig. 1 HRs for (a) cardiovascular and (b) kidney outcomes according to baseline treatment intensity. HRs cannot be directly calculated from event numbers because the trials had different randomisation ratios and different follow-up durations. The follow-up for CANVAS was 295.9 weeks and for CANVAS-R was 108.0 weeks. Cana, canagliflozin; $\mathrm{CV}$, cardiovascular; $\mathrm{HF}$, heart failure; MI, myocardial infarction 
a

\begin{tabular}{|c|c|c|c|c|}
\hline Variable & Cana & Placebo & Cana & Placebc \\
\hline $\begin{array}{l}\text { Treatment } \\
\text { intensity }\end{array}$ & \multicolumn{2}{|c|}{$\begin{array}{l}\text { Events/1000 } \\
\text { person-years }\end{array}$} & \multicolumn{2}{|c|}{ No./total no. } \\
\hline \multicolumn{5}{|l|}{ MACE } \\
\hline All & 26.9 & 31.5 & $585 / 5795$ & $426 / 4347$ \\
\hline 0 or 1 & 21.0 & 30.7 & $74 / 953$ & $72 / 740$ \\
\hline 2 & 23.0 & 24.2 & $131 / 1478$ & $81 / 1050$ \\
\hline 3 & 20.4 & 19.1 & $36 / 474$ & $21 / 352$ \\
\hline Insulin & 32.0 & 37.4 & $344 / 2890$ & $252 / 2205$ \\
\hline \multicolumn{5}{|l|}{ CV death } \\
\hline All & 11.6 & 12.8 & 268/5795 & $185 / 4347$ \\
\hline 0 or 1 & 8.0 & 13.9 & $30 / 953$ & $35 / 740$ \\
\hline 2 & 10.4 & 9.7 & $63 / 1478$ & $34 / 1050$ \\
\hline 3 & 5.9 & 6.1 & $11 / 474$ & $7 / 352$ \\
\hline Insulin & 14.3 & 15.0 & $164 / 2890$ & $109 / 2205$ \\
\hline \multicolumn{5}{|l|}{ MI } \\
\hline All & 11.2 & 12.6 & 248/5795 & $173 / 4347$ \\
\hline 0 or 1 & 10.2 & 9.7 & $36 / 953$ & $23 / 740$ \\
\hline 2 & 9.3 & 8.9 & $54 / 1478$ & $30 / 1050$ \\
\hline 3 & 10.6 & 9.0 & $19 / 474$ & $10 / 352$ \\
\hline Insulin & 12.7 & 16.1 & $139 / 2890$ & $110 / 2205$ \\
\hline \multicolumn{5}{|l|}{ Stroke } \\
\hline All & 7.9 & 9.6 & $176 / 5795$ & $133 / 4347$ \\
\hline 0 or 1 & 7.0 & 11.0 & $25 / 953$ & $26 / 740$ \\
\hline 2 & 6.9 & 8.0 & $40 / 1478$ & $27 / 1050$ \\
\hline 3 & 5.5 & 3.6 & $10 / 474$ & $4 / 352$ \\
\hline Insulin & 9.2 & 11.0 & $101 / 2890$ & $76 / 2205$ \\
\hline \multicolumn{5}{|c|}{ CV death or HF } \\
\hline All & 16.3 & 20.8 & $364 / 5795$ & $288 / 4347$ \\
\hline 0 or 1 & 12.3 & 20.5 & $44 / 953$ & $49 / 740$ \\
\hline 2 & 13.8 & 14.7 & $81 / 1478$ & $50 / 1050$ \\
\hline 3 & 11.6 & 13.5 & $21 / 474$ & $15 / 352$ \\
\hline Insulin & 19.7 & 25.0 & $218 / 2890$ & $174 / 2205$ \\
\hline
\end{tabular}

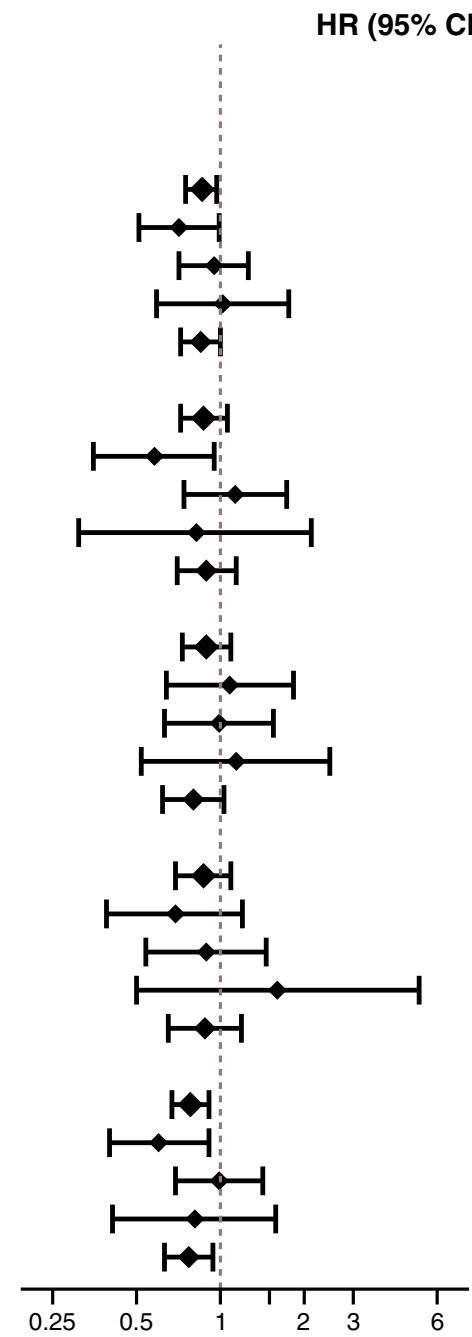

Interaction

$p$ value

0.292

$0.86(0.75,0.97)$

$0.71(0.51,0.99)$

$0.95(0.71,1.26)$

$1.02(0.59,1.76)$

$0.85(0.72,1.00)$

0.215

$0.87(0.72,1.06)$

$0.58(0.35,0.95)$

$1.13(0.74,1.73)$

$0.82(0.31,2.12)$

$0.89(0.70,1.14)$

0.476

$0.89(0.73,1.09)$

$1.08(0.64,1.83)$

$0.99(0.63,1.55)$

$1.14(0.52,2.47)$

$0.80(0.62,1.03)$

0.505

$0.87(0.69,1.09)$

$0.69(0.39,1.20)$

$0.89(0.54,1.46)$

$1.60(0.50,5.17)$

$0.88(0.65,1.19)$

$0.78(0.67,0.91)$

$0.60(0.40,0.91)$

$0.99(0.69,1.42)$

$0.81(0.41,1.58)$

$0.77(0.63,0.94)$

\section{Favours Cana Favours placebo}

\section{b}

\begin{tabular}{lcccc}
$\begin{array}{l}\text { Variable } \\
\text { Progression } \\
\text { of albuminuria }\end{array}$ & \multicolumn{2}{c}{$\begin{array}{c}\text { Cana } \\
\text { Events/1000 }\end{array}$} & $\begin{array}{c}\text { Placebo } \\
\text { person-years }\end{array}$ & \multicolumn{2}{c}{ Cana } & Placebo \\
All & 89.4 & 128.7 & $1341 / 5196$ & $1114 / 3819$ \\
$\quad$ o or 1 & 91.8 & 116.2 & $222 / 876$ & $181 / 663$ \\
2 & 83.1 & 115.4 & $337 / 1349$ & $260 / 958$ \\
3 & 83.1 & 121.0 & $107 / 437$ & $84 / 318$ \\
$\quad$ Insulin & 93.2 & 141.9 & $675 / 2534$ & $589 / 1880$ \\
\multicolumn{2}{r}{ Renal combined endpoint } & & & \\
$\quad$ All & 5.5 & 9.0 & $124 / 5794$ & $125 / 4346$ \\
0 or 1 & 4.8 & 6.7 & $17 / 952$ & $16 / 739$ \\
2 & 3.9 & 7.4 & $23 / 1478$ & $25 / 1050$ \\
3 & 2.7 & 5.3 & $5 / 474$ & $6 / 352$ \\
Insulin & 7.1 & 11.2 & $79 / 2890$ & $78 / 2205$
\end{tabular}

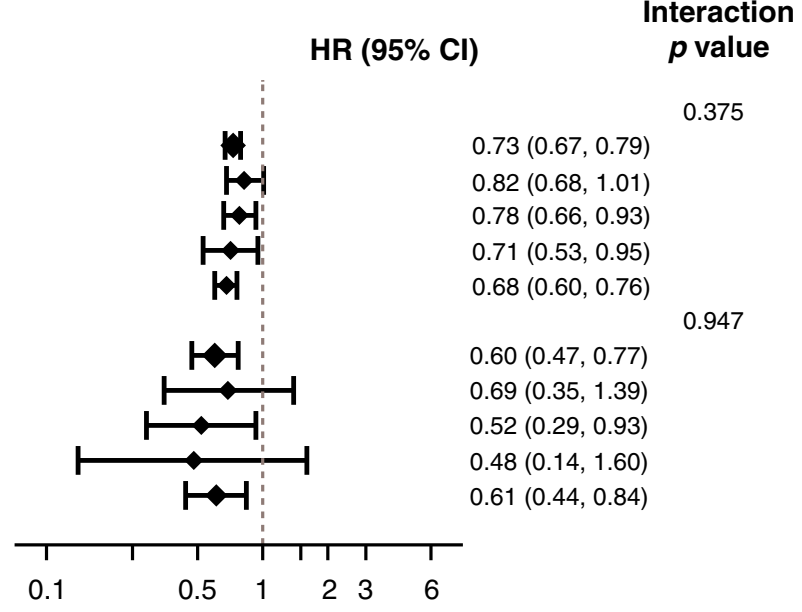

Favours Cana Favours placebo 
death, and for the protection against progression of albuminuria (p-heterogeneity 0.375 and 0.947 , respectively) (Fig. 1b).

\section{Outcomes according to disease duration}

The reduction in MACE was similar across subgroups defined by duration of diabetes $(p=0.37)$. The point estimates of the HRs suggested a potential benefit for the individual cardiovascular outcomes; however, once again, the CIs around the overall effect and the effects within each subgroup were wide and overlapped the null, so it was not possible to draw definitive conclusions (Fig. 2a). The effect of canagliflozin on myocardial infarction differed across subgroups, with no benefit seen for myocardial infarction in those with disease duration of less than 10 years ( $p$ for heterogeneity between defined subgroups $=0.01$ ). However, when considering the relative reduction in MACE, there was no evidence that the benefit differed across the range of disease duration when tested as a continuous variable (Fig. 3).

There was no evidence that the benefit differed for a reduction of the kidney disease outcome and prevention of the progression of albuminuria across subgroups of disease duration ( $p=0.773$ and 0.097 , respectively) (Fig. 2b).

\section{Outcomes according to baseline $\mathrm{HbA}_{1 \mathrm{c}}$}

For the outcome of MACE, numerically, the effects of canagliflozin appeared to be greater in the $\mathrm{HbA}_{1 \mathrm{c}}$ subgroups between 53.0 and $74.9 \mathrm{mmol} / \mathrm{mol}(7.0 \%$ and $9.0 \%)$, although this association was not seen for other cardiovascular outcomes or in analyses of $\mathrm{HbA}_{1 \mathrm{c}}$ as a continuous variable (Fig. 4). The point estimates of the HRs suggested a potential benefit for the individual cardiovascular outcomes; however, with the CIs around the overall effect and the effects within each subgroup overlapping the null, it was not possible to draw definitive conclusions (Fig. 5a).

There was no evidence that the benefit of canagliflozin for a reduction in the kidney disease outcome, and protection against progression of albuminuria, differed between subgroups defined by baseline $\mathrm{HbA}_{1 \mathrm{c}}(p=0.954$ and 0.468 , respectively) (Fig. 5b).

\section{Discussion}

In this secondary post hoc analysis of a large, multicentre randomised controlled trial, participants with type 2 diabetes randomised to canagliflozin received similar cardioprotective and renoprotective effects regardless of their baseline $\mathrm{HbA}_{1 \mathrm{c}}$, disease duration or intensity of diabetes treatment. Canagliflozin was associated with a reduction in cardiovascular death and stroke, even in participants in the highest disease duration tertile, representing at least 16 years with the disease.
Canagliflozin had consistent effects for MACE, including in participants receiving insulin at baseline. This implies a possible drug effect on the prevention of macrovascular complications that is not attenuated in those with a more complex disease state. In patients randomised to receive canagliflozin, kidney protection was observed across all variables of disease severity, including maximum treatment intensity, long disease duration and higher baseline $\mathrm{HbA}_{1 \mathrm{c}}$. Regardless of how it is defined, a higher level of baseline disease complexity or severity does not appear to pose a threshold for the cardiovascular and kidney benefits of canagliflozin.

In the absence of a clear consensus on diabetes severity categorisation, an analysis of outcomes using these three plausible variables in a trial population with a range of underlying disease complexity was undertaken. There is no universally agreed system for classifying disease severity or complexity in major international guidelines that is the equivalent of the Kidney Disease: Improving Global Outcomes (KDIGO) CKD stage classification system [21,22]. The observed concordance in findings across these three potential variables of diabetes disease complexity suggests a possible approach to systematically evaluating a disease with broad clinical presentation. This multifaceted approach for describing diabetes complexity may provide a framework for future analyses to capture a wide spectrum of disease. Overall, our broad method of describing baseline diabetes complexity, and the reproducibility of findings across all three variables, increases the generalisability of these findings to a wide range of people with type 2 diabetes.

Analyses of trial efficacy according to variables of disease complexity have been incompletely reported $[14,23,24]$. The Dapagliflozin Effect on Cardiovascular Events-Thrombolysis in Myocardial Infarction 58 (DECLARE-TIMI58) trial demonstrated heterogeneous MACE outcomes and attenuated renoprotective outcomes in patients with type 2 diabetes disease duration greater than 20 years who were randomised to receive an SGLT2 inhibitor [25]. Additionally, while major trials for cardiovascular outcomes in SGLT2 inhibitors all consider baseline $\mathrm{HbA}_{1 \mathrm{c}}$, albeit with a range of entry criteria, only one has reported outcomes according to baseline $\mathrm{HbA}_{1 \mathrm{c}}$, demonstrating that the cardioprotective effects of empagliflozin were independent of baseline glycaemic control [26]. This is concordant with our findings. Other trials do not routinely analyse outcomes according to the number of agents that patients are prescribed at study entry, or the proportion of individual agents that are used [27]. The CANVAS Program had a higher proportion of insulin use at baseline compared with other major trials, suggesting a higher proportion of participants with more complex type 2 diabetes mellitus, yet still reported favourable outcomes in this subgroup of participants. Other recent trials examining cardiovascular and kidney outcomes for novel glucose-lowering agents for diabetes other than SGLT2 inhibitors, while including a broad 
a

\begin{tabular}{|c|c|c|c|c|}
\hline Variable & Cana & Placebo & Cana & Placebo \\
\hline Diabetes duration & \multicolumn{2}{|c|}{ Events/1000 } & \multicolumn{2}{|c|}{ No./total no. } \\
\hline \multicolumn{5}{|l|}{ MACE } \\
\hline All & 26.9 & 31.5 & $585 / 5795$ & $426 / 4347$ \\
\hline$\leq 10$ & 27.2 & 27.9 & $203 / 2038$ & $132 / 1503$ \\
\hline $10-16$ & 24.8 & 30.4 & $176 / 1866$ & $138 / 1395$ \\
\hline$\geq 16$ & 28.7 & 36.6 & $206 / 1891$ & $156 / 1449$ \\
\hline \multicolumn{5}{|l|}{ CV death } \\
\hline All & 11.6 & 12.8 & $268 / 5795$ & $185 / 4347$ \\
\hline$\leq 10$ & 9.0 & 12.0 & $72 / 2038$ & $60 / 1503$ \\
\hline $10-16$ & 10.9 & 12.9 & $82 / 1866$ & $62 / 1395$ \\
\hline$\geq 16$ & 15.0 & 13.8 & $114 / 1891$ & $63 / 1449$ \\
\hline \multicolumn{5}{|l|}{ MI } \\
\hline All & 11.2 & 12.6 & $248 / 5795$ & $173 / 4347$ \\
\hline$\leq 10$ & 12.2 & 8.7 & $93 / 2038$ & $42 / 1503$ \\
\hline $10-16$ & 10.3 & 14.0 & $74 / 1866$ & $64 / 1395$ \\
\hline$\geq 16$ & 11.2 & 15.5 & $81 / 1891$ & $67 / 1449$ \\
\hline \multicolumn{5}{|l|}{ Stroke } \\
\hline All & 7.9 & 9.6 & $176 / 5795$ & $133 / 4347$ \\
\hline$\leq 10$ & 9.5 & 10.4 & $73 / 2038$ & $50 / 1503$ \\
\hline $10-16$ & 7.5 & 7.5 & $54 / 1866$ & $35 / 1395$ \\
\hline$\geq 16$ & 6.7 & 10.9 & $49 / 1891$ & $48 / 1449$ \\
\hline \multicolumn{5}{|l|}{ CV death or HF } \\
\hline All & 16.3 & 20.8 & $364 / 5795$ & $288 / 4347$ \\
\hline$\leq 10$ & 13.9 & 17.3 & $108 / 2038$ & $84 / 1503$ \\
\hline $10-16$ & 14.7 & 23.2 & $107 / 1866$ & $107 / 1395$ \\
\hline$\geq 16$ & 20.3 & 22.0 & $149 / 1891$ & $97 / 1449$ \\
\hline
\end{tabular}

HR $(95 \% \mathrm{Cl})$

Interaction

$p$ value

0.370

$0.86(0.75,0.97)$

$0.98(0.79,1.23)$

$0.82(0.65,1.02)$

$0.78(0.63,0.97)$

0.282

$0.87(0.72,1.06)$

$0.75(0.53,1.06)$

$0.82(0.59,1.14)$

$1.05(0.77,1.44)$

0.016

$0.89(0.73,1.09)$

$1.40(0.97,2.02)$

$0.76(0.54,1.06)$

$0.70(0.50,0.98)$

0.240

$0.87(0.69,1.09)$

$0.96(0.67,1.38)$

$1.03(0.67,1.58)$

$0.67(0.44,1.00)$

0.150

$0.78(0.67,0.91$

$0.80(0.60,1.07)$

$0.63(0.48,0.83)$

$0.93(0.72,1.21)$

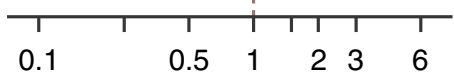

\section{Favours Cana Favours placebo}

\section{b}

\begin{tabular}{|c|c|c|c|c|}
\hline $\begin{array}{l}\text { Variable } \\
\text { Progression } \\
\text { of albuminuria }\end{array}$ & \multicolumn{2}{|c|}{$\begin{array}{l}\text { Events/1000 } \\
\text { person-years }\end{array}$} & \multicolumn{2}{|c|}{ No./total no. } \\
\hline All & 89.4 & 128.7 & $1341 / 5196$ & $1114 / 3819$ \\
\hline$\leq 10$ & 91.7 & 123.0 & 487/1879 & $383 / 1351$ \\
\hline $10-16$ & 84.7 & 116.8 & $417 / 1657$ & $344 / 1226$ \\
\hline$\geq 16$ & 91.6 & 149.0 & $437 / 1660$ & $387 / 1242$ \\
\hline \multicolumn{5}{|c|}{ Renal combined endpoint } \\
\hline All & 5.5 & 9.0 & $124 / 5794$ & $125 / 4346$ \\
\hline$\leq 10$ & 4.1 & 6.6 & $32 / 2038$ & $32 / 1502$ \\
\hline $10-16$ & 5.4 & 9.9 & 39/1865 & 46/1395 \\
\hline$\geq 16$ & 7.2 & 10.7 & $53 / 1891$ & $47 / 1449$ \\
\hline
\end{tabular}

Fig. 2 HRs for (a) cardiovascular and (b) kidney outcomes according to baseline disease duration. HRs cannot be directly calculated from event numbers because the trials had different randomisation ratios and

\section{Interaction}

$p$ value

0.097

$0.73(0.67,0.79)$

$0.79(0.69,0.91)$

$0.76(0.66,0.88)$

$0.65(0.56,0.75)$

0.773

$0.60(0.47,0.77)$

$0.62(0.38,1.02)$

$0.55(0.36,0.85)$

$0.61(0.41,0.92)$

\section{Favours Cana Favours placebo}

different follow-up durations. The follow-up for CANVAS was 295.9 weeks and for CANVAS-R was 108.0 weeks. CV, cardiovascular; HF, heart failure; MI, myocardial infarction 


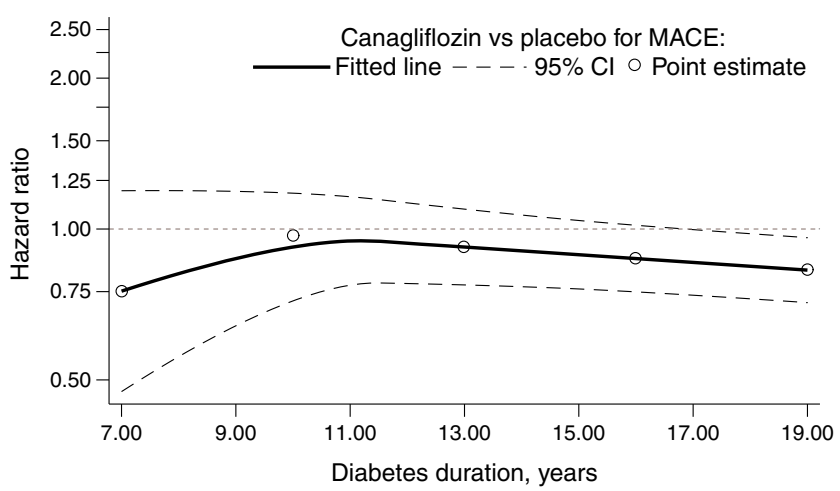

Fig. 3 Cubic spline model for HR for MACE with canagliflozin vs placebo according to baseline disease duration. The $y$-axis is plotted on a log scale

range of participants, also do not routinely attempt to stratify participants for baseline variables of pre-existing treatment intensity or disease duration [28-30]. Additionally, in trials for another novel glucose-lowering agent, glucagon-like peptide-1 (GLP-1) receptor agonists, the reported cardiovascular and kidney benefits are evident across a range of baseline diabetes variables, including those with longstanding disease and higher baseline $\mathrm{HbA}_{1 \mathrm{c}}$. While individually reported in some trials, our approach represents a novel approach to examine these three variables in parallel.

The three variables used in this analysis have clinical utility as an acceptable marker for disease complexity. There is no standard algorithm or risk score for defining this. Each of them is associated with the development of microvascular and macrovascular complications in patients with type 2 diabetes mellitus. Many patients with type 2 diabetes mellitus have an increase in treatment escalation in order to achieve glycaemic targets over time, ultimately with a high proportion progressing to insulin-based therapy [4, 31]. Additionally, other general definitions of chronic disease severity or complexity incorporate the concept of disease burden, as defined by treatment requirements such as insulin or increasing number of medications $[2,32]$. The duration of type 2 diabetes mellitus is an independent, continuous risk factor

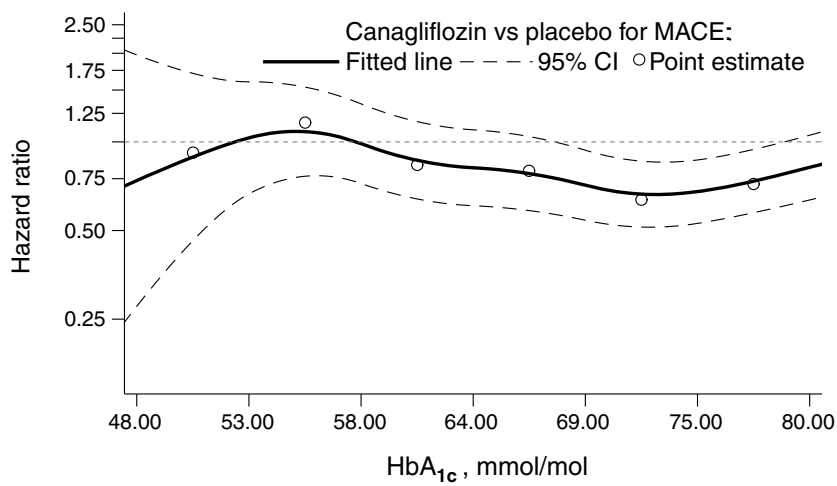

Fig. 4 Cubic spline model for HR for MACE with canagliflozin vs placebo according to baseline $\mathrm{HbA}_{1 \mathrm{c}}$. The $y$-axis is plotted on a log scale for both CVD and chronic kidney disease [5, 33]. Longer duration of disease is also associated with an increased risk of mortality, and therefore is representative of a more severe disease state [34-36]. Finally, an elevated $\mathrm{HbA}_{1 \mathrm{c}}$ is continuously associated with both the risk of complications and mortality $[8,37]$.

Poor glycaemic control is an established risk factor for increased macrovascular complications and higher rates of cardiovascular mortality $[8,38]$. This analysis did not detect a significant difference in treatment effect on the outcome of MACE across subgroups according to baseline $\operatorname{HbA}_{1 \mathrm{c}}(p=$ 0.052 , although there was a numeric trend to a greater benefit in those with higher $\mathrm{HbA}_{1 \mathrm{c}}$ at baseline). These results should be regarded cautiously given the multiple comparisons made and the post hoc nature of the analyses.

There were some risk factors that were higher in young populations. The CANVAS Program inclusion criteria were devised to recruit participants at high risk of CVD [20]. Younger participants (30-49 years) were required to have a history of symptomatic vascular disease while the presence of two or more risk factors was sufficient in participants aged 50 years and over. By their nature, the inclusion criteria introduce selection bias. This post hoc analysis of a randomised controlled trial was not designed to assess epidemiological factors.

The clinical implications of this analysis relate to both treatment effects and underlying baseline risk profile of patients with type 2 diabetes mellitus. In this analysis, kidney protection was observed in all variables of disease complexity. Our findings in patient groups with a higher risk profile of diabetic kidney disease, such as longer disease duration or elevated baseline $\mathrm{HbA}_{1 \mathrm{c}}$, are encouraging in this population group who are inherently at risk of disease progression, and concordant with the other recent large-scale trial data specifically designed to test this hypothesis [12].

The strengths of this study are the multicentre, randomised controlled trial design conducted at a high standard and with a very large number of participants. The cardiovascular and kidney outcomes were prespecified and adjudicated by expert committees.

This secondary analysis also has inherent limitations applicable to any post hoc analysis of a randomised trial. The CANVAS study was not designed to test these subgroup analyses, which should be regarded as exploratory, nor were there adjustments for multiple comparisons. Further, relatively small numbers of participants with eGFR $<45 \mathrm{ml} \mathrm{m^{-1 }}$ $[1.73 \mathrm{~m}]^{-2}$ were recruited, which limits our ability to draw definitive conclusions about the effects of canagliflozin in participants with significantly reduced kidney function. The CANVAS study recruited participants with diabetes and at high cardiovascular risk; therefore, the results may not generalise to other populations. However, the consistency of effect size on a range of cardiovascular and kidney outcomes 


\begin{tabular}{|c|c|c|c|c|}
\hline Variable & Cana & Placebo & Cana & Placebo \\
\hline $\begin{array}{l}\text { HbA1c } \\
\text { MACE }\end{array}$ & \multicolumn{2}{|c|}{ Events/1000 } & \multicolumn{2}{|c|}{ No./total no. } \\
\hline All & 26.9 & 31.5 & $585 / 5795$ & $426 / 4347$ \\
\hline$<53$ & 22.9 & 22.3 & $41 / 446$ & $22 / 300$ \\
\hline $53-58$ & 25.8 & 25.3 & $110 / 1118$ & $70 / 822$ \\
\hline $58-64$ & 25.8 & 29.7 & $116 / 1180$ & $90 / 967$ \\
\hline $64-69$ & 28.6 & 37.3 & $108 / 1010$ & $88 / 783$ \\
\hline $69-75$ & 23.0 & 40.1 & $74 / 843$ & $69 / 573$ \\
\hline$>75$ & 32.5 & 32.7 & $136 / 1198$ & $87 / 902$ \\
\hline \multicolumn{5}{|l|}{ CV death } \\
\hline All & 11.6 & 12.8 & $268 / 5795$ & $185 / 4347$ \\
\hline$<53$ & 10.0 & 11.3 & $19 / 446$ & $12 / 300$ \\
\hline $53-58$ & 12.2 & 8.8 & $55 / 1118$ & $26 / 822$ \\
\hline $58-64$ & 10.4 & 9.0 & $50 / 1180$ & $29 / 967$ \\
\hline $64-69$ & 11.8 & 18.7 & $48 / 1010$ & $47 / 783$ \\
\hline $69-75$ & 10.6 & 15.8 & $36 / 843$ & $29 / 573$ \\
\hline$>75$ & 13.5 & 14.9 & $60 / 1198$ & $42 / 902$ \\
\hline \multicolumn{5}{|l|}{ MI } \\
\hline All & 11.2 & 12.6 & $248 / 5795$ & $173 / 4347$ \\
\hline$<53$ & 11.1 & 8.0 & $20 / 446$ & $8 / 300$ \\
\hline $53-58$ & 9.3 & 11.1 & $40 / 1118$ & $31 / 822$ \\
\hline $58-64$ & 11.6 & 12.4 & $53 / 1180$ & $38 / 967$ \\
\hline $64-69$ & 11.4 & 13.4 & $44 / 1010$ & $32 / 783$ \\
\hline $69-75$ & 10.7 & 17.1 & $35 / 843$ & $30 / 573$ \\
\hline$>75$ & 13.1 & 12.7 & $56 / 1198$ & $34 / 902$ \\
\hline \multicolumn{5}{|l|}{ Stroke } \\
\hline All & 7.9 & 9.6 & $176 / 5795$ & $133 / 4347$ \\
\hline$<53$ & 7.1 & 6.9 & $13 / 446$ & $7 / 300$ \\
\hline $53-58$ & 9.0 & 7.5 & $39 / 1118$ & $21 / 822$ \\
\hline $58-64$ & 5.6 & 12.0 & $26 / 1180$ & $37 / 967$ \\
\hline $64-69$ & 8.0 & 8.7 & $31 / 1010$ & $21 / 783$ \\
\hline $69-75$ & 6.7 & 12.4 & $22 / 843$ & $22 / 573$ \\
\hline$>75$ & 10.5 & 9.2 & $45 / 1198$ & $25 / 902$ \\
\hline \multicolumn{5}{|c|}{ CV death or HF } \\
\hline All & 16.3 & 20.8 & $364 / 5795$ & $288 / 4347$ \\
\hline$<53$ & 12.5 & 16.7 & $23 / 446$ & $17 / 300$ \\
\hline $53-58$ & 14.8 & 14.8 & $65 / 1118$ & $42 / 822$ \\
\hline $58-64$ & 16.2 & 17.4 & $75 / 1180$ & $54 / 967$ \\
\hline $64-69$ & 17.1 & 27.7 & $67 / 1010$ & $67 / 783$ \\
\hline $69-75$ & 15.5 & 27.3 & $51 / 843$ & $48 / 573$ \\
\hline$>75$ & 19.3 & 22.1 & $83 / 1198$ & $60 / 902$ \\
\hline
\end{tabular}

Interaction

$p$ value

HR $(95 \% \mathrm{Cl})$

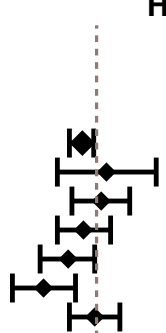

0.052

$0.86(0.75,0.97)$

$1.11(0.66,1.88)$

$1.05(0.77,1.42)$

$0.87(0.66,1.16)$

$0.74(0.55,0.98)$

$0.57(0.41,0.80)$

$0.98(0.75,1.28)$

$0.87(0.72,1.06)$

$0.97(0.46,2.02)$

$1.37(0.85,2.18)$

$1.10(0.69,1.75)$

$0.60(0.40,0.90)$

$0.64(0.39,1.06)$

$0.87(0.59,1.30)$

$0.89(0.73,1.09)$

$1.39(0.61,3.20)$

$0.86(0.54,1.38)$

$0.95(0.62,1.46)$

$0.87(0.54,1.38)$

$0.61(0.37,1.00)$

$1.00(0.65,1.54)$

$0.87(0.69,1.09)$

$1.15(0.45,2.93)$

$1.32(0.77,2.53)$

$0.50(0.30,0.84)$

$0.88(0.50,1.55)$

$0.60(0.33,1.09)$

$1.17(0.71,1.92)$

$0.78(0.67,0.91)$

$0.82(0.43,1.55)$

$1.02(0.69,1.51)$

$0.91(0.64,1.30)$

$0.63(0.44,0.89)$

$0.56(0.38,0.85)$

$0.84(0.60,1.18)$

0.160

0.464

0.055

0.087

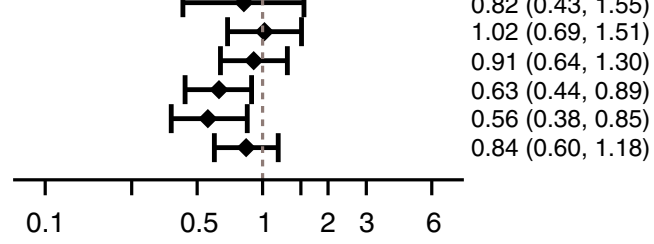

Favours Cana Favours placebo

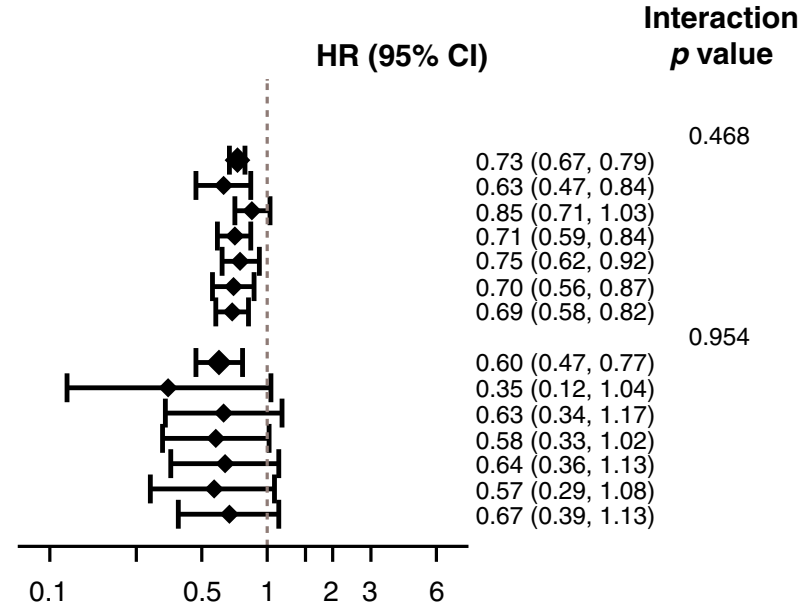

Favours Cana Favours placebo

up durations. The follow-up for CANVAS was 295.9 weeks and for CANVAS-R was 108.0 weeks. CV, cardiovascular; HF, heart failure; MI, myocardial infarction
Fig. 5 HRs for (a) cardiovascular and (b) kidney outcomes according to baseline $\mathrm{HbA}_{1 \mathrm{c}}$. HRs cannot be directly calculated from event numbers because the trials had different randomisation ratios and different follow- 
supports the likely beneficial effects of SGLT2 inhibitors in patients with type 2 diabetes mellitus at high cardiovascular risk.

Conclusions Canagliflozin has beneficial cardiovascular and kidney outcomes that are evident across a wide range of diabetes control and levels of complexity in patient groups who have an underlying elevated risk of CVD. Consideration for the clinical utility of SGLT2 inhibitors in the prevention of cardiovascular and kidney complications of diabetes across a spectrum of disease, even in those patient groups with more serious prognostic factors, is warranted.

Supplementary Information The online version of this article (https:// doi.org/10.1007/s00125-021-05524-1) contains peer-reviewed but unedited supplementary material.

Acknowledgements Some of the data were presented as an abstract at the 57th ERA-EDTA Congress in 2020.

Data availability Data from the CANVAS Program will be made available in the public domain via the Yale University Open Data Access Project (http://yoda.yale.edu/) once the product and relevant indications studied have been approved by regulators in Europe and the United States and the study has been completed for 18 months. Data are available from the authors upon reasonable request.

Funding The CANVAS Program was supported by Janssen Research \& Development, LLC; ClinicalTrials.gov registration no. NCT01032629, NCT01989754. The analyses in this paper were supported solely by the authors' institutions and received no external support. The study sponsor/ funder was not involved in the design of the study; the collection, analysis, and interpretation of data; writing the report; and did not impose any restrictions regarding the publication of the report.

Authors' relationships and activities TKY is supported by a University Postgraduate Award Scholarship to undertake a PhD at UNSW. She provides scientific support for a trial sponsored by Visterra. J-WL, AK, $\mathrm{CA}, \mathrm{CH}$ and GF declare that there are no relationships or activities that might bias, or be perceived to bias, their work. BLN has received travel support from Janssen and honoraria from Bayer with all funds paid to his institution. HJLH's institution received honoraria from Janssen. SZ reports payment to institution (Monash University) outside the submitted work-Eli Lilly Australia Ltd., Boehringer-Ingelheim, MSD Australia, AstraZeneca, Novo Nordisk and Servier. KWM has received research grants or consultancy agreements from the following: Abbott, Afferent, AHA, Amgen, Anthos, Apple, Inc., AstraZeneca, Baim Institute, Bayer, Boehringer Ingelheim, Cardiva Medical, Inc., CSL Behring, Eidos, Elsevier, Ferring, Gilead, Google (Verily), Inova, Intermountain Health, Johnson \& Johnson, Luitpold, Medscape, Medtronic, Merck, Mount Sinai, Mundipharma, Myokardia, NIH, Novartis, Novo Nordisk, Otsuka, Portola, Regeneron, Sanifit, Sanofi, SmartMedics, St. Jude and Theravance. VP reports Honoraria for Advisory Boards or Scientific Presentations: AbbVie, Bayer, Boehringer Ingelheim, GlaxoSmithKline, Janssen and Pfizer; Astellas, AstraZeneca, Bayer, Baxter, Bristol-Myers Squibb, Chinook, Durect, Eli Lilly, Gilead, Merck, Mitsubishi Tanabe, Mundipharma, Novartis, Novo Nordisk, Pharmalink, Relypsa, Retrophin, Roche, Sanofi, Servier and Vitae; and is Serving/Served on Steering Committees for trials funded by AbbVie, Astra Zeneca, Bayer, Boehringer Ingelheim, Chinook, Eli Lilly, Gilead, GlaxoSmithKline, Janssen, Novartis, Novo Nordisk and Retrophin; and is a Board Director for: George Clinical, George Institute, Garvan Institute, Mindgardens Network, Children's Cancer Institute and Victor Chang Cardiac Research Institute. DdZ provides consultancy to Janssen Fresenius, Boehringer Ingelheim, Bayer, Mitsubishi Tanabe, Mundipharma and Travere Pharma. BLN reports honoraria from Janssen and Mitsubishi Tanabe Pharma Corporation. MJ is supported by a Medical Research Future Fund Next Generation Clinical Researchers Program Career Development Fellowship; is responsible for research projects that have received unrestricted funding from Gambro, Baxter, CSL, Amgen, Eli Lilly and MSD; has served on advisory boards sponsored by Akebia, Astra Zeneca, Baxter, Boehringer Ingelheim, MSD and Vifor; serves on a Steering Committee for trials sponsored by Janssen and CSL; and has spoken at scientific meetings sponsored by Janssen, Amgen, Roche and Vifor, with any consultancy, honoraria or travel support paid to her institution.

Contribution statement All authors made substantial contributions to conception and design of the paper. TKY and J-WL undertook the initial analysis of data and all authors contributed to the interpretation of data. TKY drafted the original article and all authors contributed to revisions and final approval for publishing. TKY and MJ are responsible for the integrity of the work as a whole. The authors, who had full access to the data and made the final decisions about the content of the manuscript, vouch for the accuracy and completeness of the data and analyses and for the fidelity of the trial to the protocol.

Open Access This article is licensed under a Creative Commons Attribution 4.0 International License, which permits use, sharing, adaptation, distribution and reproduction in any medium or format, as long as you give appropriate credit to the original author(s) and the source, provide a link to the Creative Commons licence, and indicate if changes were made. The images or other third party material in this article are included in the article's Creative Commons licence, unless indicated otherwise in a credit line to the material. If material is not included in the article's Creative Commons licence and your intended use is not permitted by statutory regulation or exceeds the permitted use, you will need to obtain permission directly from the copyright holder. To view a copy of this licence, visit http://creativecommons.org/licenses/by/4.0/.

\section{References}

1. Chatterjee S, Khunti K, Davies MJ (2017) Type 2 diabetes. Lancet 389:2239-2251. https://doi.org/10.1016/S0140-6736(17)30058-2

2. Sav A, Salehi A, Mair FS, McMillan SS (2017) Measuring the burden of treatment for chronic disease: implications of a scoping review of the literature. BMC Med Res Methodol 17:140

3. American Diabetes Association (2019) 6. Glycemic targets: standards of medical care in diabetes - 2019. Diabetes Care 42:S61S70

4. Turner RC, Cull CA, Frighi V, Holman RR (1999) Glycemic control with diet, sulfonylurea, metformin, or insulin in patients with type 2 diabetes mellitus: progressive requirement for multiple therapies (UKPDS 49). UK Prospective Diabetes Study (UKPDS) Group. JAMA 281:2005-2012. https://doi.org/10.1001/jama.281. 21.2005

5. Zoungas S, Woodward M, Li Q et al (2014) Impact of age, age at diagnosis and duration of diabetes on the risk of macrovascular and microvascular complications and death in type 2 diabetes. Diabetologia 57:2465-2474. https://doi.org/10.1007/s00125-0143369-7 
6. UK Prospective Diabetes Study (UKPDS) Group (1998) Intensive blood-glucose control with sulphonylureas or insulin compared with conventional treatment and risk of complications in patients with type 2 diabetes (UKPDS 33). Lancet (London, England) 352: 837-853

7. The Diabetes Control and Complications Trial Research Group (1995) The relationship of glycemic exposure (HbA1c) to the risk of development and progression of retinopathy in the diabetes control and complications trial. Diabetes 44:968-983. https://doi. org/10.2337/diab.44.8.968

8. Zoungas S, Chalmers J, Ninomiya T et al (2012) Association of HbA1c levels with vascular complications and death in patients with type 2 diabetes: evidence of glycaemic thresholds. Diabetologia 55:636-643. https://doi.org/10.1007/s00125-0112404-1

9. Rodriguez-Gutierrez R, McCoy RG (2019) Measuring what matters in DiabetesReevaluating the use of hemoglobin A1c as a surrogate marker in diabetes. JAMA 321:1865-1866. https://doi. org/10.1001/jama.2019.4310

10. Spencer-Bonilla G, Quinones AR, Montori VM (2017) Assessing the burden of treatment. J Gen Intern Med 32:1141-1145. https:// doi.org/10.1007/s11606-017-4117-8

11. Neal B, Perkovic V, Mahaffey KW et al (2017) Canagliflozin and cardiovascular and renal events in type 2 diabetes. $\mathrm{N}$ Engl J Med 377:644-657. https://doi.org/10.1056/NEJMoa1611925

12. Perkovic V, Jardine MJ, Neal B et al (2019) Canagliflozin and renal outcomes in type 2 diabetes and nephropathy. N Engl J Med 380: 2295-2306. https://doi.org/10.1056/NEJMoa1811744

13. Wiviott SD, Raz I, Bonaca MP et al (2019) Dapagliflozin and cardiovascular outcomes in type 2 diabetes. N Engl J Med 380: 347-357. https://doi.org/10.1056/NEJMoa1812389

14. Zinman B, Wanner C, Lachin JM et al (2015) Empagliflozin, cardiovascular outcomes, and mortality in type 2 diabetes. N Engl J Med 373:2117-2128. https://doi.org/10.1056/NEJMoa1504720

15. Neuen BL, Young T, Heerspink HJL et al (2019) SGLT2 inhibitors for the prevention of kidney failure in patients with type 2 diabetes: a systematic review and meta-analysis. Lancet Diabetes Endocrinol 7:845-854

16. Neuen Brendon L, Ohkuma T, Neal B et al (2018) Cardiovascular and renal outcomes with canagliflozin according to baseline kidney function. Circulation 138:1537-1550. https://doi.org/10.1161/ CIRCULATIONAHA.118.035901

17. Petrykiv S, Sjöström CD, Greasley PJ et al (2017) Differential effects of dapagliflozin on cardiovascular risk factors at varying degrees of renal function. Clin J Am Soc Nephrol 12:751-759

18. Cherney DZI, Cooper ME, Tikkanen I et al (2018) Pooled analysis of phase III trials indicate contrasting influences of renal function on blood pressure, body weight, and $\mathrm{HbAlc}$ reductions with empagliflozin. Kidney Int 93:231-244. https://doi.org/10.1016/j. kint.2017.06.017

19. Zelniker TA, Wiviott SD, Raz I et al (2019) SGLT2 inhibitors for primary and secondary prevention of cardiovascular and renal outcomes in type 2 diabetes: a systematic review and metaanalysis of cardiovascular outcome trials. Lancet 393:31-39. https://doi.org/10.1016/S0140-6736(18)32590-X

20. Neal B, Perkovic V, Mahaffey KW et al (2017) Optimizing the analysis strategy for the CANVAS Program: a prespecified plan for the integrated analyses of the CANVAS and CANVAS-R trials. Diabetes Obes Metab 19:926-935. https://doi.org/10.1111/dom. 12924

21. Levin A, Stevens PE, Bilous RW et al (2013) Kidney disease: Improving Global Outcomes (KDIGO) CKD Work Group. KDIGO 2012 clinical practice guideline for the evaluation and management of chronic kidney disease. Kidney Int 3:1-150

22. Davies MJ, D'Alessio DA, Fradkin J et al (2018) Management of hyperglycaemia in type 2 diabetes, 2018. A consensus report by the
American Diabetes Association (ADA) and the European Association for the Study of Diabetes (EASD). Diabetologia 61: 2461-2498. https://doi.org/10.1007/s00125-018-4729-5

23. Neal B, Perkovic V, de Zeeuw D et al (2013) Rationale, design, and baseline characteristics of the Canagliflozin Cardiovascular Assessment Study (CANVAS)-a randomized placebo-controlled trial. Am Heart J 166:217-223.e211. https://doi.org/10.1016/j.ahj. 2013.05.007

24. Raz I, Mosenzon O, Bonaca MP et al (2018) DECLARE-TIMI 58: participants' baseline characteristics. Diabetes Obes Metab 20: 1102-1110. https://doi.org/10.1111/dom.13217

25. Bajaj HS, Raz I, Mosenzon O et al (2020) Cardiovascular and renal benefits of dapagliflozin in patients with short and long-standing type 2 diabetes: analysis from the DECLARE-TIMI 58 trial. Diabetes Obes Metab 22:1122-1131. https://doi.org/10.1111/dom. 14011

26. Inzucchi SE, Kosiborod M, Fitchett D et al (2018) Improvement in cardiovascular outcomes with empagliflozin is independent of glycemic control. Circulation 138:1904-1907. https://doi.org/10. 1161/CIRCULATIONAHA.118.035759

27. Zinman B, Inzucchi SE, Lachin JM et al (2014) Rationale, design, and baseline characteristics of a randomized, placebo-controlled cardiovascular outcome trial of empagliflozin (EMPA-REG OUTCOME). Cardiovasc Diabetol 13:102. https://doi.org/10. 1186/1475-2840-13-102

28. Rosenstock J, Perkovic V, Johansen OE et al (2019) Effect of linagliptin vs placebo on major cardiovascular events in adults with type 2 diabetes and high cardiovascular and renal risk: the CARMELINA randomized clinical trial. JAMA 321:69-79. https://doi.org/10.1001/jama.2018.18269

29. Marso SP, Daniels GH, Brown-Frandsen K et al (2016) Liraglutide and cardiovascular outcomes in type 2 diabetes. N Engl J Med 375: 311-322. https://doi.org/10.1056/NEJMoa1603827

30. Green JB, Bethel MA, Armstrong PW et al (2015) Effect of sitagliptin on cardiovascular outcomes in type 2 diabetes. N Engl J Med 373:232-242. https://doi.org/10.1056/NEJMoa1501352

31. Fu AZ, Sheehan JJ (2016) Treatment intensification for patients with type 2 diabetes and poor glycaemic control. Diabetes Obes Metab 18:892-898. https://doi.org/10.1111/dom.12683

32. Boyd CM, Weiss CO, Halter J et al (2007) Framework for evaluating disease severity measures in older adults with comorbidity. J Gerontol A Biol Sci Med Sci 62:286-295. https://doi.org/10.1093/ gerona/62.3.286

33. Nanayakkara N, Ranasinha S, Gadowski A et al (2018) Age, age at diagnosis and diabetes duration are all associated with vascular complications in type 2 diabetes. J Diabetes Complicat 32:279 290. https://doi.org/10.1016/j.jdiacomp.2017.11.009

34. Huo L, Magliano DJ, Ranciere F et al (2018) Impact of age at diagnosis and duration of type 2 diabetes on mortality in Australia 1997-2011. Diabetologia 61:1055-1063. https://doi.org/10.1007/ s00125-018-4544-z

35. Herrington WG, Alegre-Diaz J, Wade R et al (2018) Effect of diabetes duration and glycaemic control on 14-year cause-specific mortality in Mexican adults: a blood-based prospective cohort study. Lancet Diabetes Endocrinol 6:455-463. https://doi.org/10. 1016/S2213-8587(18)30050-0

36. Vetrone LM, Zaccardi F, Webb DR et al (2019) Cardiovascular and mortality events in type 2 diabetes cardiovascular outcomes trials: a systematic review with trend analysis. Acta Diabetol 56:331-339. https://doi.org/10.1007/s00592-018-1253-5

37. Zoungas S, Arima H, Gerstein HC et al (2017) Effects of intensive glucose control on microvascular outcomes in patients with type 2 diabetes: a meta-analysis of individual participant data from randomised controlled trials. Lancet Diabetes Endocrinol 5:431437. https://doi.org/10.1016/S2213-8587(17)30104-3 
38. Cavero-Redondo I, Peleteiro B, Álvarez-Bueno C et al (2017) Glycated haemoglobin A1c as a risk factor of cardiovascular outcomes and all-cause mortality in diabetic and non-diabetic populations: a systematic review and meta-analysis. BMJ Open 7: e015949. https://doi.org/10.1136/bmjopen-2017-015949
Publisher's note Springer Nature remains neutral with regard to jurisdictional claims in published maps and institutional affiliations. 